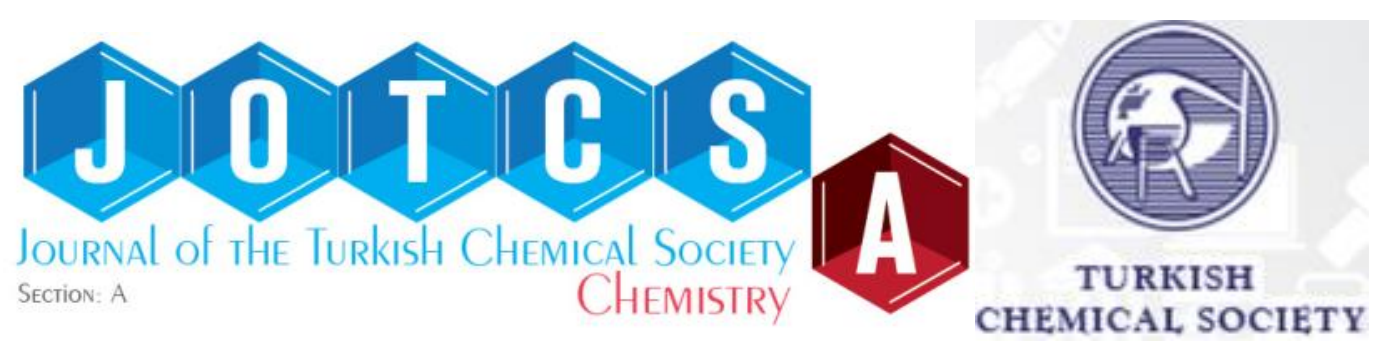

\title{
Colour Removal from Biologically Treated Textile Dyeing Wastewater with Natural and Novel Pre-Hydrolysed Coagulants
}

\author{
G.Yildiz Tore*, R.Ata, S.Özden Çelik, Ş. Kırhan Sesler \\ (This article first appeared in PPM2017 and was accepted as a non-peer-reviewed \\ manuscript to be published in JOTCSA) \\ Namık Kemal University, Çorlu Engineering Faculty, Environmental Engineering \\ Department 59860 Çorlu-TEKİRDAĞ/TURKEY
}

\begin{abstract}
In this paper, natural (chitosan and starch) and novel pre-hydrolysed coagulants (PACl, PAFC, PFS and PFC) were performed with coagulant aid for colour removal from a biologically treated textile wastewater including multiple dyes (indigo and reactive). According to the experimental results, optimum coagulant dosages which provide the best colour removal for $\mathrm{PACl}, \mathrm{PAFCl}, \mathrm{PFS}(\% 10)$ and $\mathrm{PFCl}$ (\%10), were determined as $80 \mathrm{mg} / \mathrm{L}, 10 \mathrm{mg} / \mathrm{L}, 3 \mathrm{mg} / \mathrm{L}$ and $40 \mathrm{mg} / \mathrm{L}$, respectively, at $\mathrm{pH} 4$ and $\mathrm{pH} 6,98$ (natural $\mathrm{pH}$ of studied wastewater, $\mathrm{pHnww}$ ). Maximum colour removal was determined as $97 \%$ for $\mathrm{PAFCl}$, minimum removal was $23 \%$ for $\mathrm{PFCl}$ at $\mathrm{pH} 4$, while it was calculated as $75 \%$ and $52 \%$ at pHnww. COD removal was observed as $45 \%$ at $\mathrm{pH} 4$ and $55 \%$ at pHnww for maximum colour removal. Sludge production rate was measured as $71 \mathrm{~kg} / \mathrm{d}$ while this rate was found as $60 \mathrm{~kg} / \mathrm{d}$ at pHnww. On the other hand colour removal efficiencies were determined in the range of $55-88 \%$ at $\mathrm{pHnww}$ and $\mathrm{pH} 3$ for chitosan while it was calculated as $52 \%$ for starch at $\mathrm{pHnww}$ and $\mathrm{pH}$ 9. According to the results, PAFCl and chitosan were found as the best coagulants for colour removal of investigated textile wastewater. According to the economic analysis results, the best colour effiency were found as $97 \%$ with $\mathrm{PAFCl}$ and the second best colour removal were found as $88 \%$ with Chitosan. Due to lower sludge production than PAFCl and lower chemical costs; Chitosan can be considered as a reasonable alternative for this wastewater.
\end{abstract}

Keywords: Natural and Novel pre-hydrolysed coagulant, Colour removal, Textile wastewater, PAFCl, Chitosan.

Cite this: Yıldız Töre G, Ata R, Özden Çelik S, Kırhan Sesler Ş. Colour Removal from Biologically Treated Textile Dyeing Wastewater with Natural and Novel PreHydrolysed Coagulants. JOTCSA. 2018;5(sp. is. 1):23-36.

*Corresponding author. E-mail: gyildiztore@nku.edu.tr. 


\section{INTRODUCTION}

Textile industry use huge amount of water and complex hazardous chemicals at various processing stages of the textile materials. The unused parts of these chemicals are discharged as wastewater that is high in temperature, biochemical oxygen demand (BOD), chemical oxygen demand (COD), colour, $\mathrm{pH}$, turbidity and toxic chemicals. Conventional chemical and biological treatment methods are widely applied in the textile and other coloured wastewater. Although these systems are succesfull to remove the conventional parameters, textile influents containing especially different types of dyes which have high molecular weight and complex structures, show very low biodegradability in terms of colour removal and so, they are insufficient to provide the discharge standarts for receiving bodies (1). In this context, it is very important to decide which approach is the most suitable for colour removal from textile wastewater in terms of environment. Generally, wastewater containing dyes is difficult to treat due to the nature of the dye. Most of the dyes are stable against to light and oxidizing agents and are resistant to biologic degradation. The most used technologies to treat wastewater containing dyes are based on physical-chemical and/or biological processes. Coagulation and sedimentation processes are known to be effective in eliminating the colours of insoluble dyes such as disperse ones. However, these are not conditions for soluble dyes including reactive dyes (2). The well-known conventional coagulants such as alum, polyaluminum chloride, iron(II) sulfate and lime are widely used in textile wastewater treatment. More than $90 \%$ of colour removal from acid dyes could be achieved by activated carbon. However, it is not effective coagulant for basic and direct dyes (3). Chemical coagulation has a complex structure involving various interacted parameters, therefore it must be defined how well coagulant will function under given conditions. On the basis of colour removal, chemical coagulants can be categorised as hydrolysing metallic salts, pre-hydrolysing metallic salts and synthetic cationic polymers, respectively (4). Recently, the usage of natural (chitosan, starch derivatives, guar gum, tannins, alginates exct.) and novel hydrolysed polymers (polyaluminium chloride $(\mathrm{PACl})$, polyaluminium ferric chloride $(\mathrm{PAFCl})$, polyferrous sulphate (PFS) and polyferric chloride $(\mathrm{PFCl})$ ) in wastewater treatment application have increased rapidly $(1,5,6)$. It is reported in the literature that these polymers are more efficient than conventional inorganic coagulants for especially colour removal due to the synergistic effect of two different coagulant substances in a single substance (6). The literature studies have reported that novel pre-hydrolysed coagulants such as polyaluminium chloride $(\mathrm{PACl})$, polyaluminium ferric chloride $(\mathrm{PAFCl})$, polyferrous sulphate (PFS) and polyferric chloride $(\mathrm{PFCl})$ have an advantage that good colour removal even at low temperature. Another advantage 
of these coagulant is to produce lower volume of sludge compared to conventional coagulants. In this context, the effectiveness of various novel pre-hydrolysing coagulants for the treatment of textile wastewater have been studied in the literature recently. These studies mostly reported that both they don't need $\mathrm{pH}$ correction, additional coagulant aid etc. $(1,4,7)$. When the literature studies done with PACL are examined; it has been found that PACl provides stronger and rapidly settleable floc formation, which causes faster flocculation than that of alum at the same dose $(7,8)$. Studies, run in textile wastewaters with PAFCl are very limited in the literature. In the study performed by Gao et al. in 2001, it was found that PAFCl is more effective in colour and turbidity removal than PACl and PFS for the wastewater of the petrochemical industry at $\mathrm{pH} 7.0-8.4$. It is shown that floc formation occured faster than the other coagulants. The coexistence of aluminum and iron ions in PAFCl has been found to result in faster floc formation, sedimentation and hence more efficient colour removal (8). In a study conducted by Wang et al. (2008) on textile wastewater with PFS; in the case of $150 \mathrm{mg} / \mathrm{L}$ PFS applied to wastewater at $\mathrm{pH}$ 9, it was found that $71 \% \mathrm{COD}, 56 \% \mathrm{BOD}, 62 \% \mathrm{AKM}$ and $>50 \%$ colour removal were achieved (9). When literature studies done with PFCl are examined; in studies published by Wang et al. in 2010, ferric chloride $\left(\mathrm{FeCl}_{3}\right), \mathrm{PFCl}$ and polydimethyldiallylammonium chloride (PDMDAAC) flocculants in textile wastewaters were compared for colour removal. It has been found that the combined use of the flocculants in the study gives more successful results. It has been reported that the combination of $\mathrm{FeCl}_{3}-$ PDMDAAC and $\mathrm{PFCl}$ - PDMDAAC is more effective in colour removal than conventional use (10). A study done by Chen et al. for a synthetic dyed textile wastewaters in 2010, PFCl and polyamine (EPI-DMA) were investigated for colour removal and flocking performance at different concentrations. Colour removal for direct yellow 201 and remazol red 24 were obtained as $98 \%$ and $19 \%$ with $\mathrm{PFCl}$ at $\mathrm{pH} 7.5$. It was found that in the combination of PFCl / EPI-DMA, the colour removal were found $97.5 \%$ for remazol red 24 and direct yellow 201 at pH 6.0 and flock formation has been found to give better results (11). In the study conducted by Wei et al., the effects of different dosages of $\mathrm{PFCl} / \mathrm{PDMDAAC}$ combinations on the colour removal and flocculation dynamics of reactive and disperse dyeing textile wastewaters were investigated. $60 \%$ of reactive dyes, $95.5 \%$ of colour removal in disperse dyes and the highest rate of floc formation were determined with $30 \mathrm{mg} / \mathrm{L} \mathrm{PFCl} /$ PDADMAAC application (12).

Many natural plant and non-plant derived polymers such as chitosan, starch, guar gum, arabic gum, moringa, tannin, cactus etc. are known as natural coagulants. There are limited studies carried out with starch for coagulation of industrial wastewater. In a study conducted by Hasçakır in 2003 with starch coagulation; 85-90\% and 20\% 
COD removal have been achieved for paper industry wastewater and domestic wastewater, respectively. In the same study, 70-75\% COD removal and 30-35\% COD removal in domestic wastewater were detected when starch was used as a flocculant together with alum, lime and ferric chloride, but no study was made on the formation and amount of sludge (13). Chitosan is obtained from the fleece material based on the shells of red-crusted crabs and shrimps and proved an adsorbent and/or coagulant characteristics. Chitosan has high cationic charge density with long polymer chains leading to bridging of aggregation and precipitation behave as a biological cationic polymer. Numerous works have demonstrated that chitosan can be a potential alternative to conventional coagulation/flocculation application for waste water treatment to remove both particulate and dissolved substances. However, more studies are required to optimize the process. Sanghi and Bhattacharya (2005) showed that chitosan is very effective as a coagulant aid to remove acidic and direct dyes. They also reported that reactive dyes with anthraquinone groups were the most difficult to remove with chitosan and PAC (14). Gandjidoust et al. (1997) reported that chitosan resulted in the higher removal in both colour and TOC than synthetic polymers (poly(acrylmide) or PAM, poly(ethyleneimine) or PEI) and a chemical coagulant (alum) (15). Similar results were reported by Rodrigues et al. (2008) and Wang et al. (2007) for the treatment of pulp and paper mill wastewater. These groups have also proposed modified chitosan-based biopolymers as adsorbents and/or coagulants for the removal of SS, COD and colour from pulp and paper mill effluent $(16,17)$. In addition, these coagulants, which will not interfere with biological treatment due to the fact that the coagulant residue can serve as a nutrient for microorganisms and novel properties of natural coagulants having the biodegradable nature of non-toxic biodegradable properties, can be regarded as promising coagulant and coagulant aid for the treatment of textile wastewater, especially for the first stage.

The aim of this study is to evaluate the colour removal efficiency of biologically treated textile dyeing wastewater, including multiple dyes (indigo and reactive), with natural and novel pre-hydrolysed coagulants and to describe optimum conditions $(\mathrm{pH}$, coagulant dosage, sludge volume etc.) based on the economically achievable best removal efficiency. 


\section{MATERIAL AND METHODS}

\section{Materials}

This study was carried out in the wastewater treatment system treating denim washing $(70 \%)$ and reactive dyeing $(30 \%)$ wastewater located in Çorlu town of Tekirdağ. Treatment system has a $1500 \mathrm{~m}^{3} / \mathrm{d}$ capacity composed of physical and biological treatment units including conventional activated sludge processes. Treated wastewater has been discharged in a receiving body called Sinanlı stream. Experimental studies were carried out on treated wastewater samples to characterize wastewater for one year. For wastewater characterisation; between 2013/ NovemberDecember and 2014/January, daily composite samples were taken from the biological treatment effluent, which were called 'raw wastewater' in chemical experimental study results.

\section{Coagulants and Coagulation/ Floculation test procedure (Jar Test)}

All natural and novel pre-hydrolysed coagulants were supplied as analytical grade. Only PFCl was prepared according to the method used by Jincheng Wei et.al. (18). All coagulation/ flocculation experiments were conducted in one liter glass beakers using a conventional Jar-test apparatus (VELP Scientifica, FC6S) equipped with four beakers. $1000 \mathrm{~mL}$ stock solutions of each polymer were prepared $10 \% \mathrm{w} / \mathrm{w} .1 \mathrm{~mL}$ (2 $\mathrm{mg} / \mathrm{L}$ ) anionic polyelectolite was used as coagulant aids for each coagulant. The sollutions were stirred rapidly at $200 \mathrm{rpm}$ for 2 min during the addition of coagulants, followed by slow stirring at $45 \mathrm{rpm}$ for $15 \mathrm{~min}$ and settling for $30 \mathrm{~min}$. After settling, supernatant samples were collected and filtered using coarse filter for further analysis. Optimum conditions were assessed for colour and COD removal before treatability experiments were started. Jar test trials were made at efficient $\mathrm{pH}$ intervals (acidic, basic and real ww), mixing rate and flocculant dosage which is determined in treatability pre-studies for each coagulant. The $\mathrm{pH}$ of the samples were adjusted to acidic and basic conditions by adding $1 \mathrm{~N} \mathrm{HCl}$ or $\mathrm{NaOH}$ solutions for all coagulants. After then, supernatant and sludge characterisation were carried out on the samples for the determination of best options.

\section{Analytical Methods}

All analyses were performed according to the standard methods [Standart Methods, 1998] except COD and colour parameters. The COD and colour were measured according to ISO 6060 Method [ISO 6060, 1986] and ISO 7887 method [ISO 7887, 1987], respectively. The adjustment of $\mathrm{pH}$ was carried out using a (WTW pH315i) pH meter. The colour of the supernatant after jar test was determined by the spectral absorption coefficient (SAC) method. Percentage of SAC removal was calculated based 
on absorbance measurements by the spectrophotometer at three different wavelengths $(\lambda=436,525$ and 620$)$.

\section{RESULTS AND DISCUSSION}

\section{Effluent Characterisation}

Wastewater characterisation is given at Table 1 . It shows that colour parameter as a pollution parameter does not achieve the discharge criteria defined in the European Standard EN ISO 7887 for receiving environment although organic content and $\mathrm{pH}$ values are enough low for receiving body. So, it needs to further chemical treatment to achive the discharge standarts determined in Turkey.

Table 1: Wastewater characterisation of investigated treatment plant.

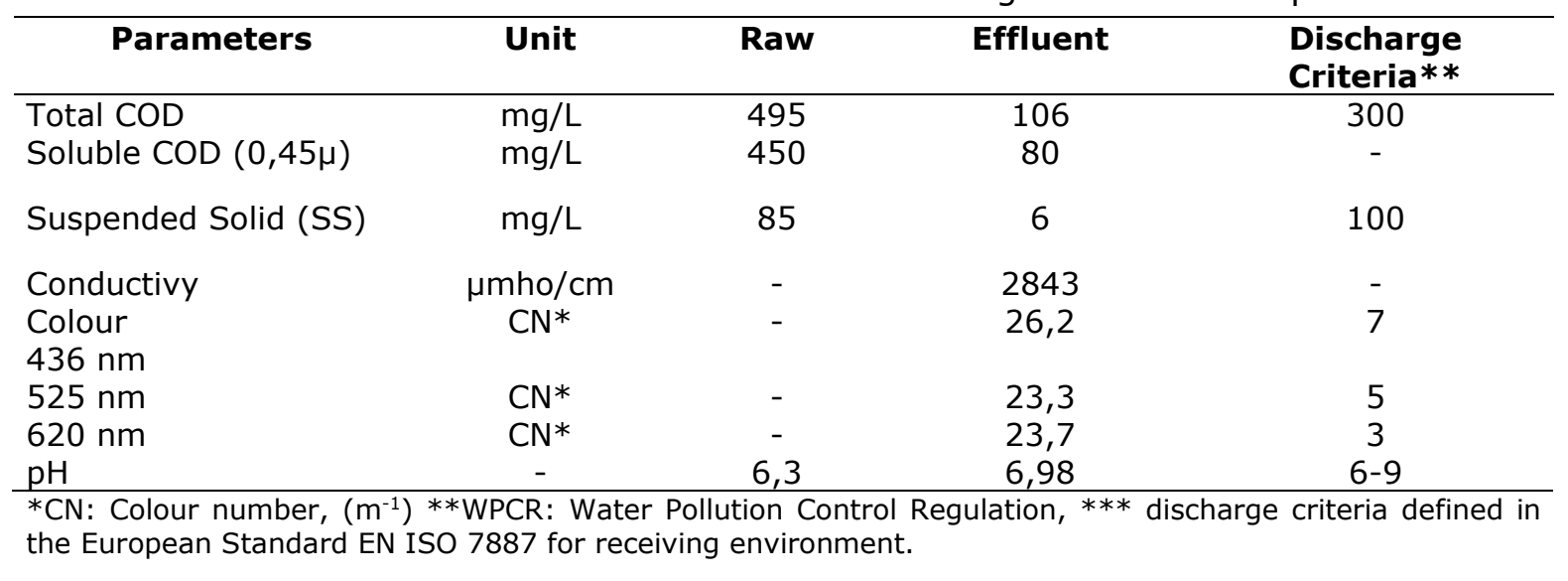

\section{Jar Test results}

Optimum conditions were determined for colour and COD removal, and sludge production were evaluated under these optimum conditions. Comperative results of jar tests were given at Table 2. According to the jar test results, carried out at the determined optimum dosages, maximum colour removal was calculated as $97 \%$ for $\mathrm{PAFCl}$, while minimum removal determined as $23 \%$ at $\mathrm{pH} 4$ with. For maximum colour removal, sludge production rate was measured as $71 \mathrm{~kg} / \mathrm{d}$ while this rate was found as $60 \mathrm{~kg} / \mathrm{d}$ at pHnww. On the other hand, COD removal was measured as $55 \%$ at this maximum colour removal. Maximum colour removal was calculated almost close together at pHnww as $\approx 75 \%$ for PAFCL and PACl. Tun et all. (2007) studied at $\mathrm{pH}: 7.5$ and similar colour removal efficiencies $(75 \%)$ have been obtained with the dose of PACl as high as $800 \mathrm{mg} / \mathrm{L}$ (19). 
Table 2: Comperative removal efficiencies and sludge production.

\begin{tabular}{|c|c|c|c|c|c|c|c|c|c|c|c|}
\hline \multicolumn{12}{|c|}{ COLOUR REMOVAL } \\
\hline \multicolumn{2}{|c|}{$\begin{array}{c}80 \mathrm{mg} / \mathrm{L} \mathrm{PACl} \\
(10 \%)+ \\
1 \mathrm{ml}(1 / 500) \\
\text { A.P.E }\end{array}$} & \multicolumn{2}{|c|}{$\begin{array}{c}10 \mathrm{mg} / \mathrm{L} \\
\text { PAFCl }(10 \%) \\
+1 \mathrm{ml} \\
(1 / 500) \text { A.P.E }\end{array}$} & \multicolumn{2}{|c|}{$\begin{array}{c}3 \mathrm{mg} / \mathrm{L} \\
(10 \%) \text { PFS+ } \\
2 \mathrm{ml} 1 / 500 \\
\text { A.P.E }\end{array}$} & \multicolumn{2}{|c|}{$\begin{array}{c}40 \mathrm{mg} / \mathrm{L} \\
\mathrm{PFCl}+1 \mathrm{ml} \\
1 / 500 \text { A.P.E }\end{array}$} & \multicolumn{2}{|c|}{$\begin{array}{c}600 \mathrm{mg} / \mathrm{L} \\
\text { Starch }+0.3 \\
\text { ml } 1 / 500 \\
\text { A.P.E }\end{array}$} & \multicolumn{2}{|c|}{$\begin{array}{c}4.5 \mathrm{mg} / \mathrm{L} \\
\text { chitosan+ } 0.1 \\
\text { ml } 1 / 500 \\
\text { A.P.E }\end{array}$} \\
\hline $\mathrm{pH} 4$ & $\begin{array}{c}\mathrm{pHnw} \\
\mathrm{w}\end{array}$ & $\mathrm{pH} 4$ & $\begin{array}{c}\text { pHnw } \\
\text { w }\end{array}$ & $\mathrm{pH} 4$ & $\begin{array}{c}\mathrm{pHnw} \\
\mathrm{w}\end{array}$ & $\mathrm{pH} 4$ & $\begin{array}{c}\mathrm{pHnw} \\
\mathrm{w}\end{array}$ & $\begin{array}{c}\mathrm{pHnw} \\
\mathrm{w}\end{array}$ & $\mathrm{pH} 9$ & $\begin{array}{c}\mathrm{pHnw} \\
\mathrm{w}\end{array}$ & $\mathrm{pH} 3$ \\
\hline $\begin{array}{l}76 \\
\%\end{array}$ & $74 \%$ & $\begin{array}{l}97 \\
\%\end{array}$ & $75 \%$ & $\begin{array}{l}79 \\
\%\end{array}$ & $48 \%$ & $\begin{array}{l}23 \\
\%\end{array}$ & $52 \%$ & $52 \%$ & $\begin{array}{l}52 \\
\%\end{array}$ & $55 \%$ & $\begin{array}{l}88 \\
\%\end{array}$ \\
\hline \multicolumn{12}{|c|}{ COD REMOVAL } \\
\hline \multicolumn{2}{|c|}{$\begin{array}{l}80 \mathrm{mg} / \mathrm{L} \mathrm{PACl} \\
(10 \%)+1 \mathrm{ml} \\
(1 / 500) \text { A.P.E }\end{array}$} & \multicolumn{2}{|c|}{$\begin{array}{c}10 \mathrm{mg} / \mathrm{L} \\
\mathrm{PAFCl}(10 \%) \\
+1 \mathrm{ml} \\
(1 / 500) \text { A.P.E }\end{array}$} & \multicolumn{2}{|c|}{$\begin{array}{c}3 \mathrm{mg} / \mathrm{L} \\
(10 \%) \text { PFS+ } \\
2 \mathrm{ml} 1 / 500 \\
\text { A.P.E }\end{array}$} & \multicolumn{2}{|c|}{$\begin{array}{c}40 \mathrm{mg} / \mathrm{L} \\
\mathrm{PFCl}+1 \mathrm{ml} \\
1 / 500 \text { A.P.E }\end{array}$} & \multicolumn{2}{|c|}{$\begin{array}{c}600 \mathrm{mg} / \mathrm{L} \\
\text { Starch }+0.3 \\
\mathrm{ml} 1 / 500 \\
\text { A.P.E }\end{array}$} & \multicolumn{2}{|c|}{$\begin{array}{c}4.5 \mathrm{mg} / \mathrm{L} \\
\text { chitosan+ } 0.1 \\
\text { ml } 1 / 500 \\
\text { A.P.E }\end{array}$} \\
\hline \multicolumn{2}{|c|}{ pHnww } & $\mathrm{pH} 4$ & $\begin{array}{c}\mathrm{pHnw} \\
\mathrm{w}\end{array}$ & $\mathrm{pH} 4$ & $\begin{array}{c}\mathrm{pHnw} \\
\mathrm{w}\end{array}$ & $\mathrm{pH} 4$ & $\begin{array}{c}\mathrm{pHnw} \\
\mathrm{w}\end{array}$ & $\begin{array}{c}\mathrm{pHnw} \\
\mathrm{w}\end{array}$ & $\mathrm{pH} 9$ & \multicolumn{2}{|c|}{$\mathrm{pH} 3$} \\
\hline \multicolumn{2}{|c|}{$53 \%$} & $\begin{array}{l}55 \\
\%\end{array}$ & $45 \%$ & $\begin{array}{l}47 \\
\%\end{array}$ & $67 \%$ & $\begin{array}{l}67 \\
\%\end{array}$ & $63 \%$ & $60 \%$ & $\begin{array}{l}65 \\
\%\end{array}$ & \multicolumn{2}{|c|}{$56 \%$} \\
\hline \multicolumn{12}{|c|}{ SLUDGE PRODUCTION (kg/day) } \\
\hline \multicolumn{2}{|c|}{$\begin{array}{l}80 \mathrm{mg} / \mathrm{L} \mathrm{PACl} \\
(10 \%)+1 \mathrm{ml} \\
(1 / 500) \text { A.P.E }\end{array}$} & \multicolumn{2}{|c|}{$\begin{array}{c}10 \mathrm{mg} / \mathrm{L} \\
\mathrm{PAFCl}(10 \%) \\
+1 \mathrm{ml} \\
(1 / 500) \text { A.P.E }\end{array}$} & \multicolumn{2}{|c|}{$\begin{array}{c}3 \mathrm{mg} / \mathrm{L} \\
(10 \%) \text { PFS+ } \\
2 \mathrm{ml} 1 / 500 \\
\text { A.P.E }\end{array}$} & \multicolumn{2}{|c|}{$\begin{array}{c}40 \mathrm{mg} / \mathrm{L} \\
\mathrm{PFCl}+1 \mathrm{ml} \\
1 / 500 \text { A.P.E }\end{array}$} & \multicolumn{2}{|c|}{$\begin{array}{c}600 \mathrm{mg} / \mathrm{L} \\
\text { Starch }+0.3 \\
\mathrm{ml} 1 / 500 \\
\text { A.P.E }\end{array}$} & \multicolumn{2}{|c|}{$\begin{array}{c}4.5 \mathrm{mg} / \mathrm{L} \\
\text { chitosan+ } 0.1 \\
\text { ml } 1 / 500 \\
\text { A.P.E }\end{array}$} \\
\hline $\mathrm{pH} 4$ & $\begin{array}{c}\mathrm{pHnw} \\
\mathrm{w}\end{array}$ & $\mathrm{pH} 4$ & $\begin{array}{c}\mathrm{pHnw} \\
\mathrm{w}\end{array}$ & $\mathrm{pH} 4$ & $\begin{array}{c}\mathrm{pHnw} \\
\mathrm{w}\end{array}$ & $\mathrm{pH} 4$ & $\begin{array}{c}\mathrm{pHnw} \\
\mathrm{w}\end{array}$ & $\begin{array}{c}\mathrm{pHnw} \\
\mathrm{w}\end{array}$ & $\mathrm{pH} 9$ & $\begin{array}{c}\mathrm{pHnw} \\
\mathrm{w}\end{array}$ & $\mathrm{pH} 3$ \\
\hline 56 & 79 & 71 & 60 & 31 & 14 & 123 & 148 & 509 & 560 & 123 & 24 \\
\hline
\end{tabular}

Maximum COD removal efficiencies were obtained at pHnww with PFS and PFCl as $67 \%$ and $63 \%$, respectively. Minimum COD removal was determined as $45 \%$ at the same pH. Wang et al. (2008) obtained similar results with high dose of PFS (150 $\mathrm{mg} / \mathrm{L}$ ) at $\mathrm{pH}$ 9. Wang et al. (2008) studied with denim washing wastewater and obtained $71 \%$ COD, $56 \%$ BOD and $50 \%$ colour. In our study, similar colour removal results were obtained at pHnww, while relatively higher colour removal (79\%) has been obtained with as low as $3 \mathrm{mg} / \mathrm{L}$ of PFS dose at $\mathrm{pH} 4$ (9).

Comperative results obtained in present study were given in Fig. 1-6. 


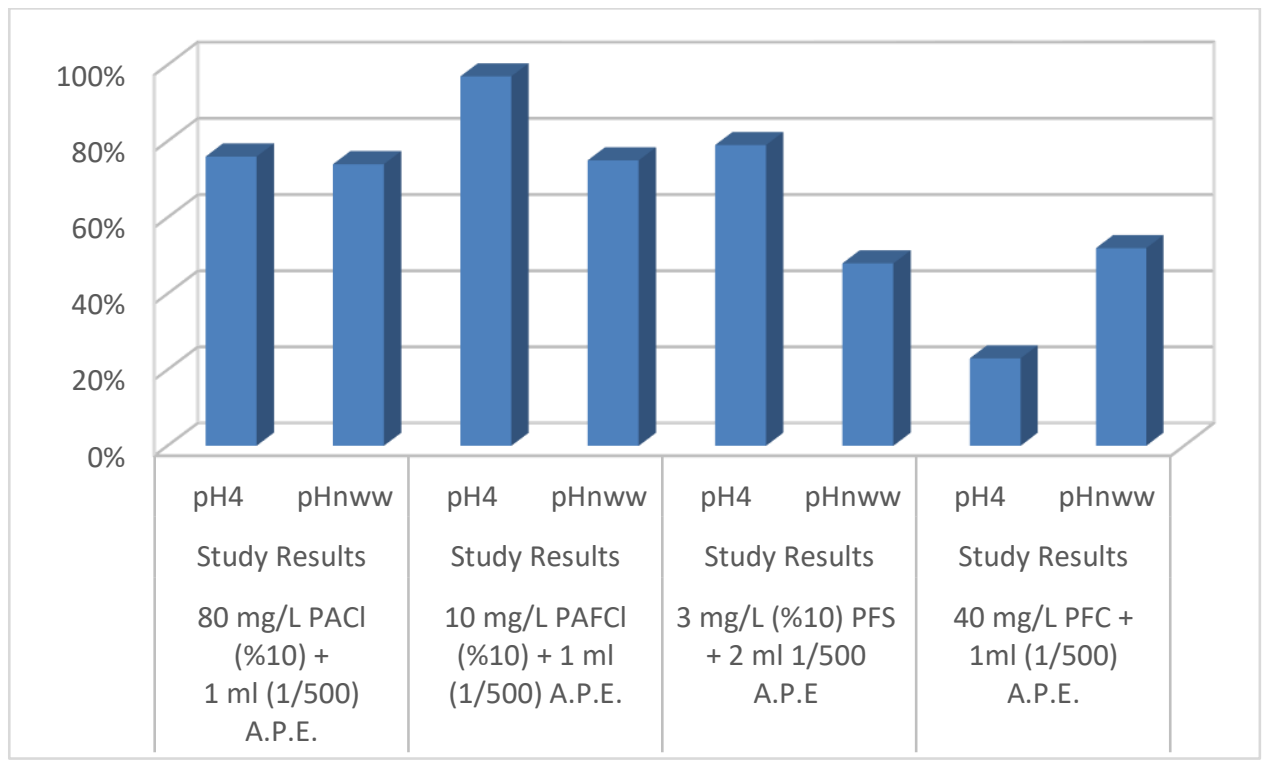

Figure 1: Comperative Colour Removal Results Obtained with Pre-hydrolized Metal Salts.

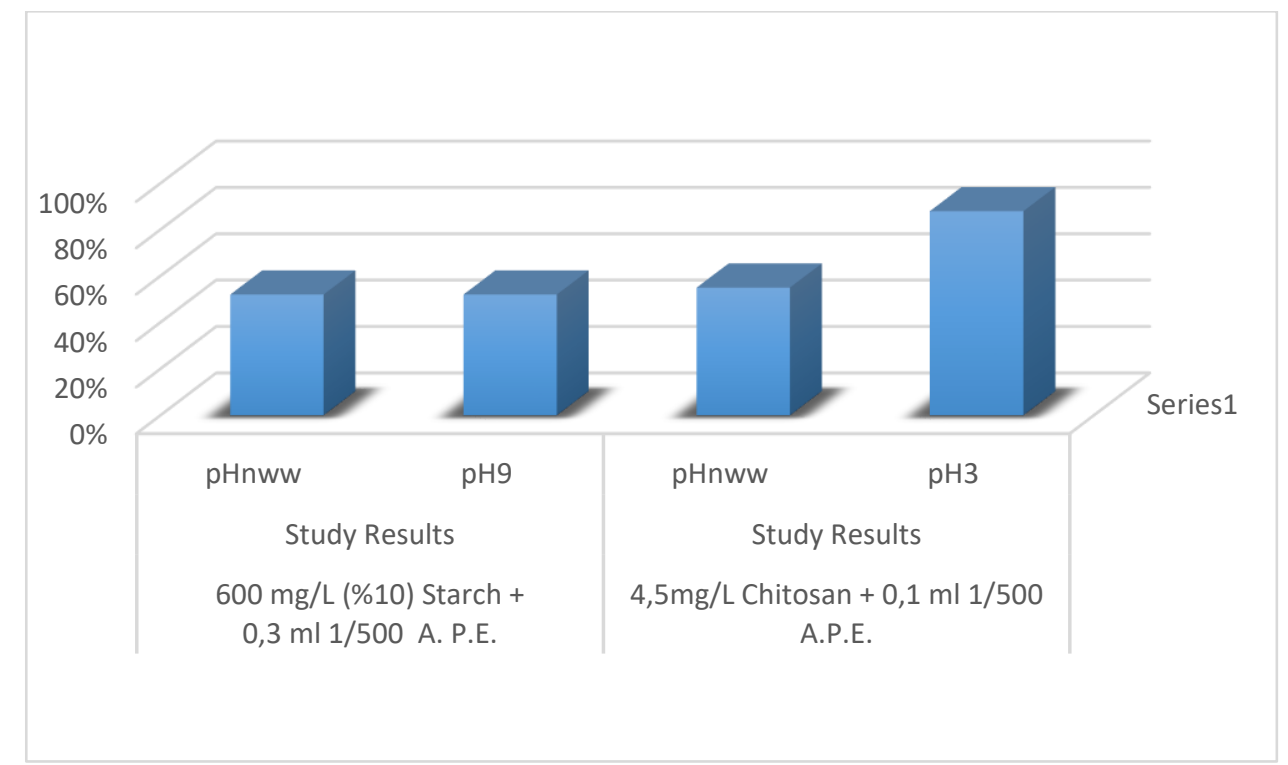

Figure 2: Comparative Colour Removal Results Obtained with Natural Coagulant.

Colour removal efficiency was determined as $52 \%$ for $\mathrm{PFCl}$ at pHnww. Chen et al. (2010) evaluated yellow 201 and remazol red removal from synthetic wastewater at $\mathrm{pH} 7.5$ and obtained $98 \%$ and $19 \%$ colour removal, respectively (11). Our results obtained with $\mathrm{PFCl}$ is relatively lower, can be attributed to usage of real wastewater. In addition, Wei et al. (2009) obtained $95.5 \%$ of colour removal with disperse dye, while only $60 \%$ of colour removal can be achieved with reactive dye (12). Considering the reactive consistency of the given wastewater used in our study, our results are similar to the literature. 


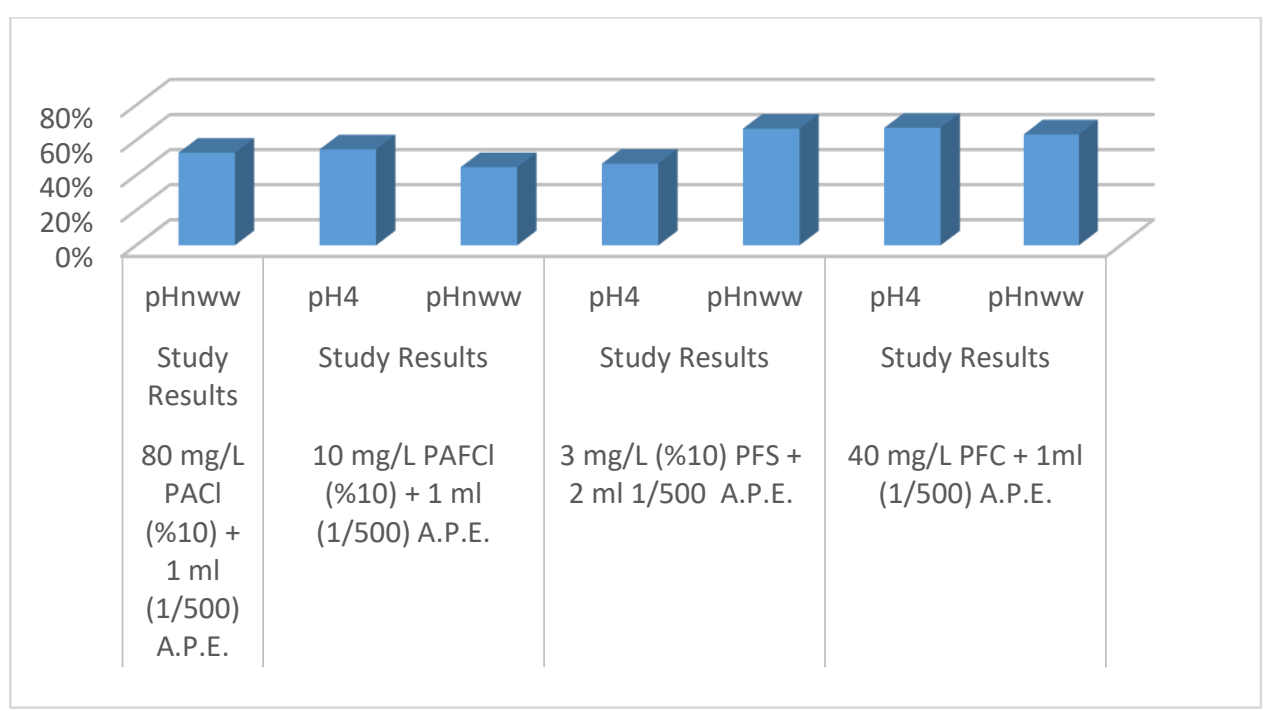

Figure 3: Comperative COD Removal Results Obtained with Pre-hydrolized Metal Salts.

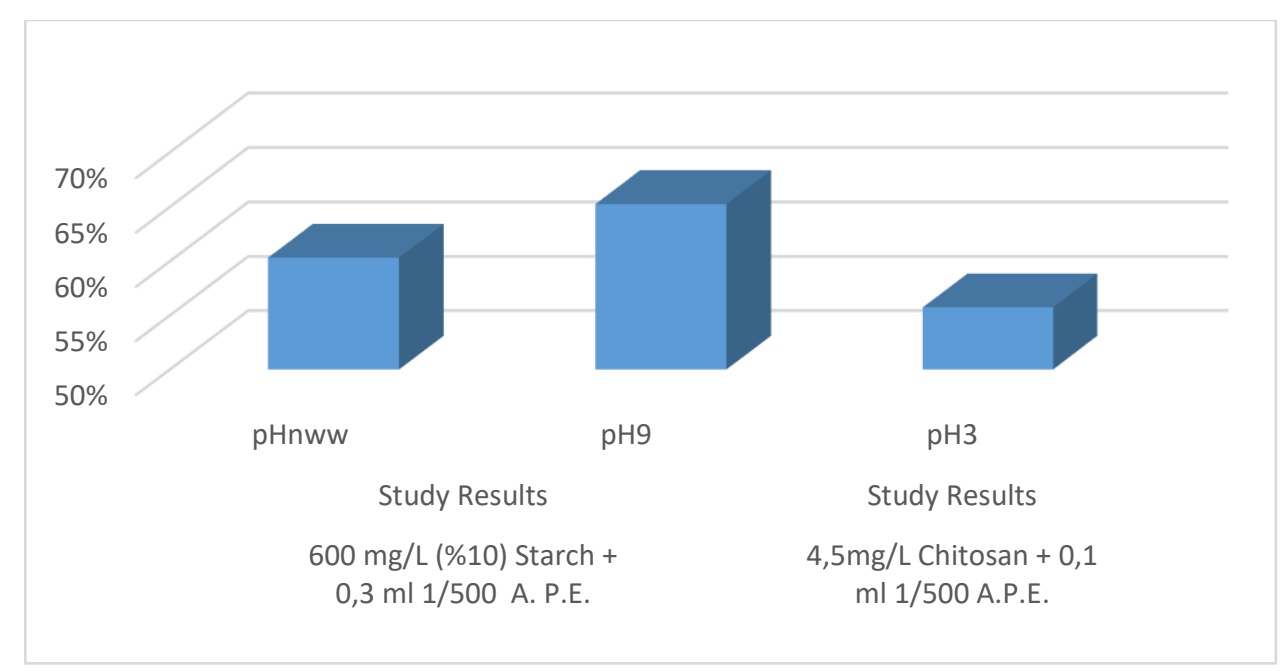

Figure 4: Comperative COD Removal Results Obtained with Natural Coagulant.

In this study $88 \%$ colour removal was obtained with $4,5 \mathrm{mg} / \mathrm{L}$ chitosan at $\mathrm{pH} 3$. This removal rate obtained in accordance with the literature. Szygula et al. (2009) obtained 99\% colour removal for Acid Blue 92 with $100 \mathrm{mg} / \mathrm{L}$ chitosan at pH 9 (20). Mahmoodi et al. (2011) reported $75 \%$ and $95 \%$ colour removal for Acid Green 25 and Direct Red 23 at pH 2 (21). 


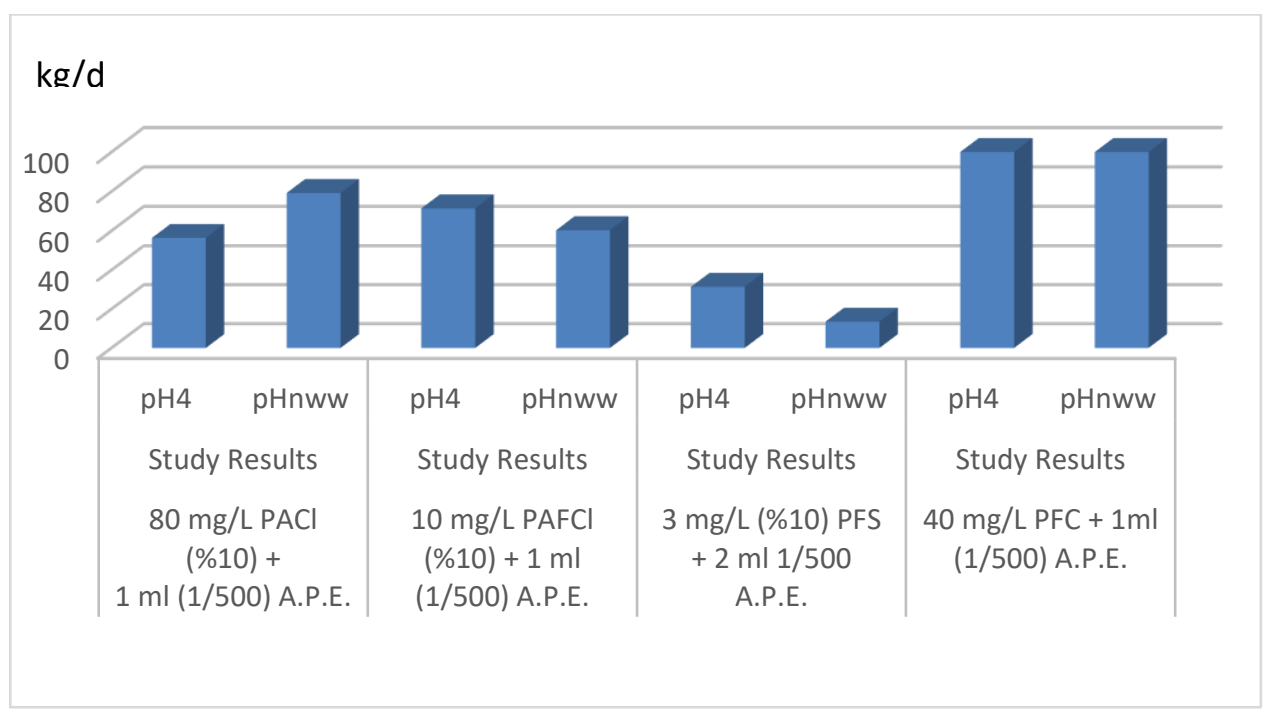

Figure 5: Comperative Sludge Production Potential Obtained with Pre-hydrolized Metal Salts.

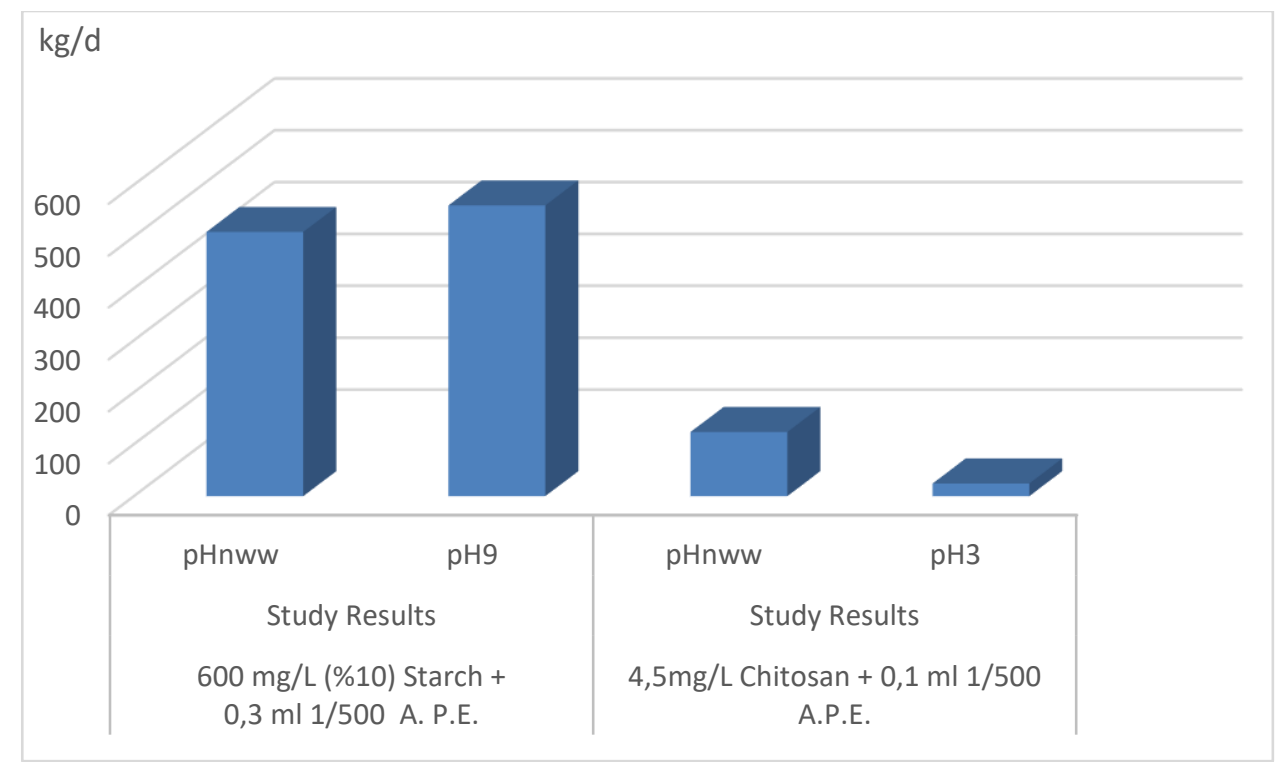

Figure 6: Comperative Sludge Production Potential Obtained with Natural Coagulants.

On the basis of daily sludge production, maximum sludge production was observed for starch at $\mathrm{pH}$ 9, while minimum was measured for PFS at pHnww. While colour removal efficiencies were determined as $52 \%$ for starch both at pHnww and $\mathrm{pH} 9$, very important difference was found for chitosan between at $\mathrm{pHnww}$ and $\mathrm{pH} 3$. However, although $\mathrm{pH} 3$ seems very efficient condition for colour removal with chitosan, this efficiency range was found to be lower than the maximum removal efficiency obtained for PAFCl as novel-prehydrolysed coagulant and also after coagulation, there is need a neutralisation. It should be considered that this results in an increase in the operating cost. 


\section{Economic Analysis}

According to the economic analysis results, daily cost with PACl was determined as 81 $\$ / \mathrm{d}$ at pHnww. Daily cost were $81 \$ / \mathrm{d}$ at same $\mathrm{pH}$, while it increased to $27 \$ / \mathrm{d}$ at $\mathrm{pH} 4$ for PAFCl. This difference results from the addition of $\mathrm{pH}$ adjustment cost. Daily cost with PFS was found as $7 \$ / d$ and $20 \$ / d$ for pHnww and pH 4, respectively. While daily cost with PFCl is calculated as $16 \$ / \mathrm{d}$ and $29 \$ / \mathrm{d}$ for pHnww and $\mathrm{pH} 4$, respectively. Starch produce $1 \$ / \mathrm{d}$ as coagulant cost, similarly chitosan produce $0,01 \$ / \mathrm{d}$ coagulant cost for $\mathrm{pHnww}$, while, $14 \$ / \mathrm{d}$ coagulant cost was calculated for chitosan at $\mathrm{pH} 3$. As it clearly shown that most of the cost is originate from the requirement of $\mathrm{pH}$ adjustment. Pollutant removal may be the major criteria for the selection of appropriate coagulant, $\mathrm{pH}$ adjustment should not be excluded. Nevertheless, sludge disposal costs were excluded in this study, therefore this situation should also be considered for total cost.

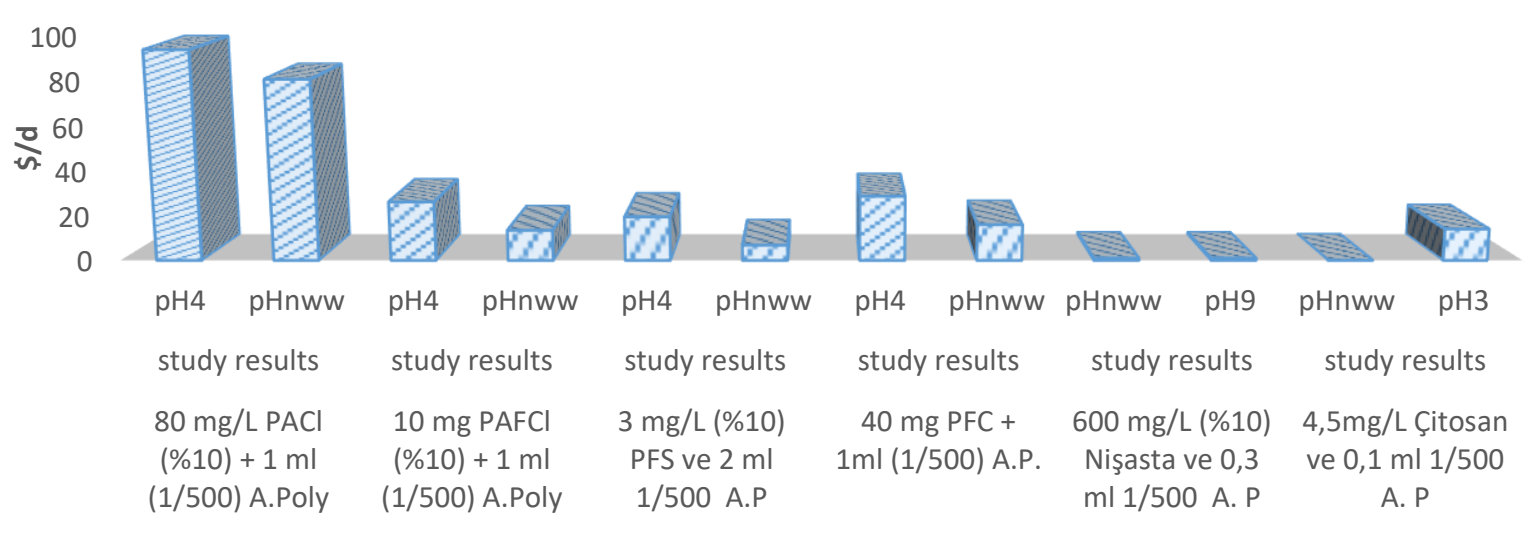

Figure 7: Comparative Coagulant Cost.

\section{CONCLUSION}

The effectiveness of various novel pre-hydrolysing coagulants ( $\mathrm{PACl}, \mathrm{PAFCl}, \mathrm{PFS}$ and $\mathrm{PFCl}$ ) for the treatment of textile wastewater have been studied in this study. Chitosan as a biological cationic polymer and as a natural coagulant, has also been investigated for textile wastewater. The results of this study may be drawn as follows:

- Maximum colour removal (97\%) was obtained with PAFCl at pH 4, while PFCl gave the minimum colour removal $(23 \%)$ at same $\mathrm{pH}$. Chitosan yielded the second maximum colour removal as $88 \%$ at $\mathrm{pH} 3.55 \%$ and $56 \% \mathrm{COD}$ removal was obtained at $\mathrm{pH} 4$ and $\mathrm{pH} 3$ for $\mathrm{PAFCl}$ and chitosan, respectively. 
- Maximum COD removal (67\%) was obtained with PFS and PFCl, at pHnww and $\mathrm{pH} 4$, respectively.

- It was shown that PACl, PAFCl, PFS and chitosan caused considerably lower sludge production. It has been found that as novel pre-hydrolysed and natural coagulant materials, PAFCl and chitosan are the best coagulants in terms of colour removal for investigated textile wastewater. Both of these coagulant are able to provide the receiving bodies discharge standards (for colour and COD removal efficiencies determined in Turkish regulations) at both natural and adjusted $\mathrm{pH}$ samples, like reported in the literature for textile wastewaters. Sludge production rates were measured for these coagulants as $60 \mathrm{~kg} / \mathrm{d}$ and $24 \mathrm{~kg} / \mathrm{d}$, respectively. PFS gave minimum sludge production (14 $\mathrm{kg} / \mathrm{d}$ ) at pHnww, while maximum sludge production was observed with starch $(560 \mathrm{~kg} / \mathrm{d})$ at $\mathrm{pH} 9$.

- According to the economic analysis results, the best colour effiency were found as $97 \%$ with $\mathrm{PAFCl}$ and the second best colour removal were found as $88 \%$ with Chitosan. Due to lower sludge production than PAFCl and lower chemical costs; Chitosan can be assessed as the optimum chemical for this wastewater.

- When the operating cost is evaluated on the basis of daily coagulant requirement, $\mathrm{PACl}$ gave the maximum cost at $\mathrm{pH} 4$. Minimum daily coagulant cost obtained as 0,01 \$/d with chitosan for pHnww. PAFCl gave 14 $\$ / \mathrm{d}$ at natural wastewater $\mathrm{pH}$.

- So, in the future, it is necessary to evaluate the cost of residual sludge disposal of both coagulants in order to be able to decide the most suitable colour removal method for investigated wastewater.

\section{ACKNOWLEDGEMENT}

This paper was produced by associated with a Msc. Thesis titled as 'Determination of the best available coagulation/flocculation technologies for colour removal from a treated textile industrial wastewater originated from the processes including indigo fabric washing together with cotton fabric dyeing' funded by the Scientific Research Council of Namık Kemal University via Grant No. NKU BAP.00.17.YL.14.02

\section{REFERENCES}

1. Yildiz Tore G, Çelik S.Ö, Gürkan R, Kırhan Sesler Ş. Determination of the Best Available Coagulatıon/Flocculatıon Technology with novel pre-hydrolysed coagulants for colour removal from biologically treated textile wastewater. Journal of Selçuk University. 2014; 1-12. 
2. Robinson T, McMullan G, Marchant R, Nigam P. Remediation of dyes in textile effluent: a critical review on current treatment technologies with a proposed alternative. Bioresource Technology. 2001; 77: 247-255.

3. Shin C.H. and Bae J.S. A stability study of an advanced co-treatment system for dye wastewater reuse. J. Ind. Eng. Chem. 2012; 18: 775-779.

4. Akshaya K.V, Rajesh R. D, Puspendu B. A review on chemical coagulation/flocculation technologies for removal of colour from textile wastewaters. Journal of Environmental Management. 2012; 93: 154-168.

5. Mohammed A.D, Hendriks J. Effective Removal of Heavy Metal Ions Using Glycerol and Starch Xanthate. JOTCSA. 2017; 4(3): 1031-1044.

6. Jiang J.Q. and Graham N.J.D. Pre-polymerised inorganic coagulants and phosphorus removal by coagulation-a review. Water SA. 1998; 24: 237-244.

7. Gregory J, Rossi L. Dynamic testing of water treatment coagulants. Water Science and Technology. 2001; 1: 65-72.

8. Gao B, Yue Q, Miao J. Evaluation of polyaluminium ferric chloride (PAFC) as a composite coagulant for water and wastewater treatment. Water Science and Technology. 2001; 47 (1): 127-132.

9. Wang X, Zeng G, Zhu, J. Treatment of jean-wash wastewater by combined coagulation, hydrolysis/acidification and Fenton oxidation. J Hazard Mater. 2008;153(1-2):810-6.

10. Wang R.M, Wang Y, He Y.F, Li F.Y, Zhou Y, He N.P. Preparation of solid composite polyferric sulfate and its flocculation behavior for wastewater containing high concentration organic compounds. Water Science and Technology. 2010; 61(11):2749 - 2757.

11. Chen $\mathrm{T}$, Gao B, Yue Q, 2010. Effect of dosing method and pH on colour removal performance and floc aggregation of polyferricchloride-polyaminedualcoagulant in synthetic dyeing wastewater treatment. Colloids and Surface A: Physicochemical and Engineering Aspects. 2010; 355: 121-129.

12. Wei J, Gao B, Yue Q, Wang, Y. Effect of dosing method on colour removal performance and flocculation dynamics of polyferric-organic polymer dual-coagulant in synthetic dyeing solution. Chemical Engineering Journal. 2009; 151 (1-3):176-182.

13. Hascakir B, Utilization Of Natural Polyelectrolytes In Wastewater Treatment. İzmir. Master thesis. Graduate School of Natural and Applied Sciences of Dokuz Eylül University. 2003.

14. Sanghi R. and Bhattacharya B. Comparative evaluation of natural polyelectrolytes psyllium and chitosan as coagulant aids for decolourisation of dye solutions. Water Quality Research Journal of Canada. 2005; 40: 97-101.

15. Ganjidoust H, Tatsumi K, Yamagishi T, Gholian RN. Effect of synthetic and natural coagulant on lignin removal from pulp and paper wastewater. Wat. Sci. Technol. 1997; 35: 291-296. 
16. Rodrigues AC, Boroski M, Shimada NS, Garcia JC, Nozaki J, Hioka N. Treatment of paper pulp mill wastewater by coagulation- flocculation followed by heterogenous photocatalysis. J. Photochem Photobiol A Chem. 2008; 194: 1-10.

17. Wang JP, Chen YZ, Ge XW, Yu HQ. Optimization of coagulation- flocculation process for a paper-recycling wastewater treatment using response surface methodology. Colloids Surf $A$ Physicochem Eng Aspects. 2007; 302: 204-210.

18. Jincheng Wei, A, Baoyu G, Qinyan Y, Yanfstarch W. Effect of dosing method on colour removal performance and flocculation Dynamics of polyferric-organic polymer dual-coagulant in synthetic dyeing solution. Chemical Engineering Journal. 2009; 151: 176-182.

19. Tun L.L, Baraoidan W.A, Gaspillo P.D, Suzuki M. A study on the relative performance of different coagulants and the kinetics of COD in the treatment of a textile bleaching and dyeing industrial wastewater. ASEAN Journal of Chemical Engineering. 2007; 7: 49-60.

20. Szyguła A, Guibal E, Ariño Palacín M, Ruiz M, Sastre AM. Removal of an anionic dye (Acid Blue 92) by coagulation-flocculation using chitosan. J Environ Manage. 2009 J;90(10):2979-86.

21. Mahmoodi NM, Salehi R, Arami M, Bahrami H. Dye Removal from Coloured Textile Wastewater Using Chitosan in Binary Systems. Desalination. 2011; 267(1): 64-72. 